\title{
Temporal SMAS Lift Using Serdev Sutures ${ }^{\circledR}$
}

\author{
Nikolay P. Serdev \\ New Bulgarian University, Sofia, Bulgaria
}

Address for correspondence:

Dr. Nikolay Serdev, MD, PhD

Honorary Professor, New Bulgarian University

Director, Medical Centre "Aesthetic Surgery, Aesthetic Medicine"

Address: 11, 20 April Str., 1606 Sofia, Bulgaria,

Phone: +359885719696,

Fax: +35929515668

www.cosmeticsurgery.bg/en

Copyright (C) 2014 Nikolay P. Serdev. This is an open access article distributed under the Creative Commons Attribution License, which permits unrestricted use, distribution, and reproduction in any medium, provided the original work is properly cited.

\begin{abstract}
Closed approach transcutaneous Serdev Suture ${ }^{\circledR}$ lifts encompass the principale concept of stable suturing and fixation of mobile fascias to immobile periosteum, tendons and fascias, resulting in suture suspension and/or volume augmentation and/or repositioning.

21 techniques and individual modifications are used on face and in body areas, even where open surgical techniques cannot be directly applied. Serdev Sutures ${ }^{\circledR}$ in the temporal area are scarless and uncomplicated in the post-operative period. These techniques use curved semiblunt semi-elastic needles and smooth surgical sutures to elevate and fixate mobile fascial tissue. Polycon surgical sutures are preferred for these techniques. They are characterized by short elasticity to prevent mobilized tissue from rupture and are characterized by delayed absorption (in 2-3 years, after the fibrosis is finalized). This enables stable fibrotic fixation before suture degradation.

Fixed mobile facial tissue using Serdev Sutures ${ }^{\circledR}$ is SMAS in all face areas: In Temporal SMAS lift it is the galea aponeurotica, which is fixed by a transcutaneous suture to the stable periosteum at the upper temporal line and the temporal fascia.
\end{abstract}


In addition to the possibility of Temporal SMAS lifting, Serdev Sutures ${ }^{\circledR}$ follow aesthetic principles of beautification: adaptation of aesthetic proportions, volumes and angles. In art and theatre, face masks called "mask of tragedy" and "mask of comedy" are well known and used to express age, status and emotions. The concept of scarless suture lift in face is to convert the "mask of tragedy" into a "mask of comedy", i.e. to uplift the subcutaneous facial mask - the SMAS. As soft tissue and skin are attached to the SMAS by a trabecular system, an intrinsic consequence of SMAS lifting is reflected in the lifting of the face and its most important elements in the same direction.

The structuring and positioning of different face elements is not limited to facial ptosis and elderly cases. Unaesthetic face angles, volumes and proportions are responsible for lack of beauty in young patients as well. Beautification is most important in youth and rejuvenation incl. beautification in elderly. Changing SMAS position by sutures can restore aesthetic angles, shape, volume and proportions as a basis for beautification and rejuvenation, imparting a happy, youthful appearance and a smiling expression.

\section{INTRODUCTION}

The scarless temporal closed approach SMAS suture lift performed exclusively with skin perforations was introduced by the author in 1990, using traditional surgical instrumentation, which was inadequate and not appropriate for such transcutaneous suture fixation. The author's needles and semi-elastic surgical sutures used for scarless SMAS lifting were introduced in 1993. In 1994 the author became a pioneer in introducing the concept of a scarless ambulatory Temporal SMAS lift using sutures, based on the anatomical fact that lifting the supra-zygomatic SMAS causes a lift effect of the infra-zygomatic SMAS. His innovation was presented and demonstrated around the world and became a routine ambulatory procedure for beautification and rejuvenation.

After Mitz and Peyronie first described the superficial muscle-aponeurotic system, or SMAS in 1976, the SMAS facelift became the usual and obligatory method for a surgical facelift. Since skin and soft tissue strongly fixed to the SMAS in the temporal region, the lifting of the SMAS in a temporal direction causes lifting of the upper, middle and to certain degree the lower facial areas including their most important elements, in the same direction.

\section{Anatomic landmarks of the temporal area and the SMAS}

During the aging process, the cranium shrinks and facial fat volume changes (in most cases increases), ptosis occurs (including the SMAS), along with skin laxity and non-elasticity. These factors change the facial expression into a sad and tired looking face. Lifting the SMAS and attaching it at a superior position allows repositioning of the other soft tissue facial structures, which are fixed to the SMAS. Aesthetically wrong face angles make young people look sad thus the objective of the temporal SMAS lift in this young population is simply beautification, based on facial aesthetics. 
The SMAS is spread from the cranium to the platysma muscles. It lies superficially to facial nerves. The SMAS acts as a suspension for the overlying facial skin and distributes muscle forces to create facial expression.

The mobile Galea aponeurotica represents the superior part of the SMAS. It is a muscleaponeurotic tissue and extends from the vertex to the brow and the zygoma. It is also known as the superficial temporal fascia, but it does not cover only the temporal area. The temporal region or "temporal pocket" is located over the temporal muscle, bordered superiorly by the superior temporal line, medially by the lateral orbital rim and inferiorly by the zygomatic arch. The immobile layer, covering the temporalis muscle, is a bright and thick aponeurosis called the Temporalis Fascia also known as the "deep temporal fascia".

At the level of the superior orbital rim, the immobile temporal fascia (or deep temporal fascia) splits into two layers, both immobile: Superficial and Deep layer of the Temporalis fascia (also named deep temporal fascia)(Fig. 7). These two fascial layers: Superficial and Deep layer of the temporalis fascia enclose intermediate fat, including a facial nerve and blood vessels.

Both mobile galea aponeurotica and immobile temporal fascia are described with different names that could cause confusion in understanding the difference between the mobile superficial temporal fascia (galea aponeurotica) that should be lifted and the immobile Superficial layer of the Temporalis fascia that is dangerous to perforate, because of the underlying neurovascular bundle.

In order to avoid confusion and misunderstanding of the anatomical explanations in this book, we shall from now on use only the terms "galea aponeurotica" (or "galea") and "temporalis fascia".

\section{Danger Area}

The author considers the area covering the immobile Superficial layer of the Temporalis fascia and the underlying neurovascular bundle (i.e. the area of $3 / 3 \mathrm{~cm}$ in front of the tragus and above the zygomatic bone) a "Danger Area" for needle perforation. In this area, the needle used for lifting must be inserted superficially just below the skin and galea aponeurotica.

Deeper penetration should be avoided in order to prevent perforation of the underlying superficial layer of the temporalis fascia and the neurovascular bundle. Pressure applied for at least $10 \mathrm{~min}$ is described by some authors to be useful in cases of trauma and bleeding in that area.

An important landmark in the temporal region is the superficial temporal artery that can easily be palpated along the hairline - the vein follows in the same direction. The frontal branch of the facial nerve, which innervates the frontalis muscle, the orbicularis oculi and corrugator supercilii lies in the intermediate fat interposed between the suprazygomatic extension of the 
SMAS below and the deep and superficial layer of the temporalis fascia (or deep temporalis fascia). The nerve travels along an imaginary line connecting the base of the tragus to a point $1.5 \mathrm{~cm}$ above the eyebrow.

Keeping in mind the neurovascular topographic position, the temporal suture lift should be performed inside the hairline. The safe area to enter the galea aponeurotica and lift it is inside the hairline and above the danger area $(3 \mathrm{~cm}$ in front of the tragus and $3 \mathrm{~cm}$ above the zygomatic bone).

\section{THE PROCEDURE}

The concept of the scarless closed approach transcutaneous temporal suture lifting is to lift the loose mobile galea and to attach it to the stable immobile upper temporalis line, periosteum and temporalis fascia. Skin adhering to the galea accompanies this repositioning in a temporal direction, thus creating a facelift. To obtain this lift, the author's proprietary curved semiblunt, semi-elastic Serdev ${ }^{\circledR}$ needles with different lengths $-50 \mathrm{~mm}, 60 \mathrm{~mm}$, and $100 \mathrm{~mm}$ long - are used to suture mobile to immobile tissue. After testing different surgical sutures the author has proven the superiority of the semi-elastic, braided, antimicrobial Bulgarian polycaproamide (Polycon) sutures USP 2 or 4 with an absorption time of two years (after the final formation of fibrosis) and prefers to use these sutures. Other sutures could be used, but because of facial movement, the limited elasticity of the Bulgarian surgical sutures reduces trauma to the lifted tissues. In the author's opinion, a more rigid and thinner suture, such as USP $2 / 0$ can act as a scalpel and when under tension can cut though the lifted tissue, causing loss of the lift effect.

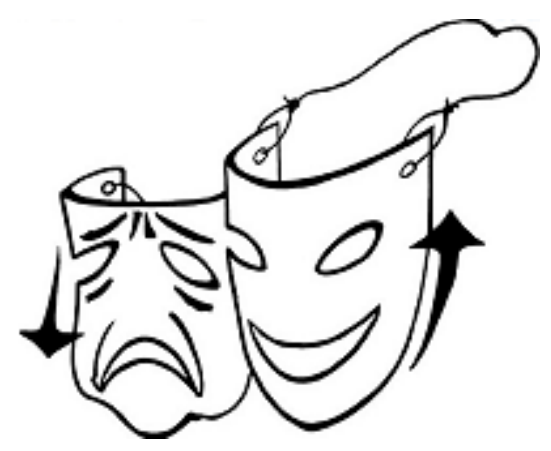

Fig.1. Mechanism of temporal SMAS lift - lifting of the "facial mask". Effect on facial structures. Transforming the old appearance into a young one. In ancient theatres these masks are known as "Mask of tragedy" and "Mask of comedy". 


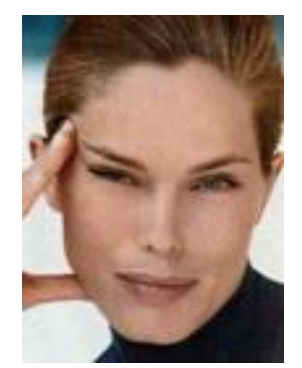

Fig. 2. The idea of a temporal lift is easily created in any woman's mind, beautiful or not. Women without any exception think about a temporal face lift.

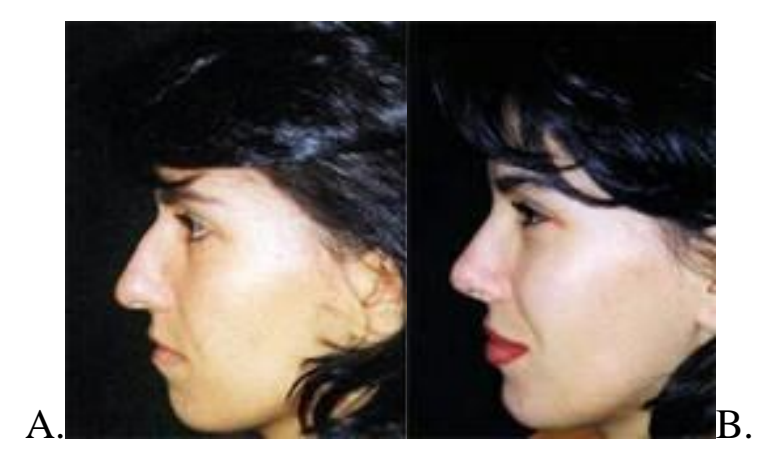

Fig. 3. A. Before and B. after simultaneously performed: 1. Temporal SMAS lift changes the hanging eyebrow tail, lateral canthus angle of the eye and even oral commissure. Better expression of cheek-bone prominence, due to lifting of the skin and the fat pad; 2. Additional rhinoplasty (author's "T-excision" technique to lift the tip and "columella sliding" to project the tip, together with hump removal) is performed to correct the "golden rule" of facial proportions in 3 equal parts; 3. Lip WY-plasty augmentation has equalized lip and eye volume; 4. Chin augmentation by suture has obtained the "beauty triangle" and the "straight line of the profile". Embellishment of the face is obtained and "smiling" expression is present ("mask of comedy" = fresh and young look).

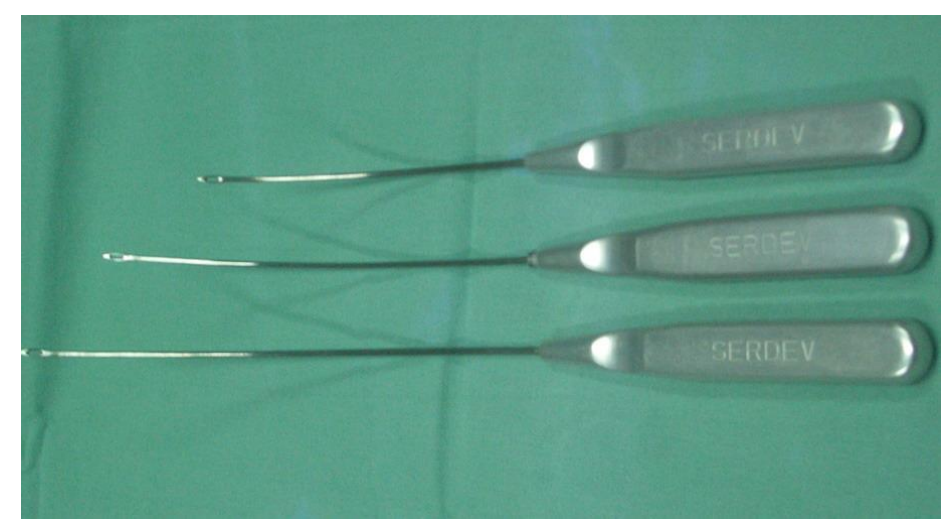

Fig 4. Curved semi-blunt and semi-elastic needles with lengths of 50mm, 60mm and $100 \mathrm{~mm}$, used for temporal suture lifts. 


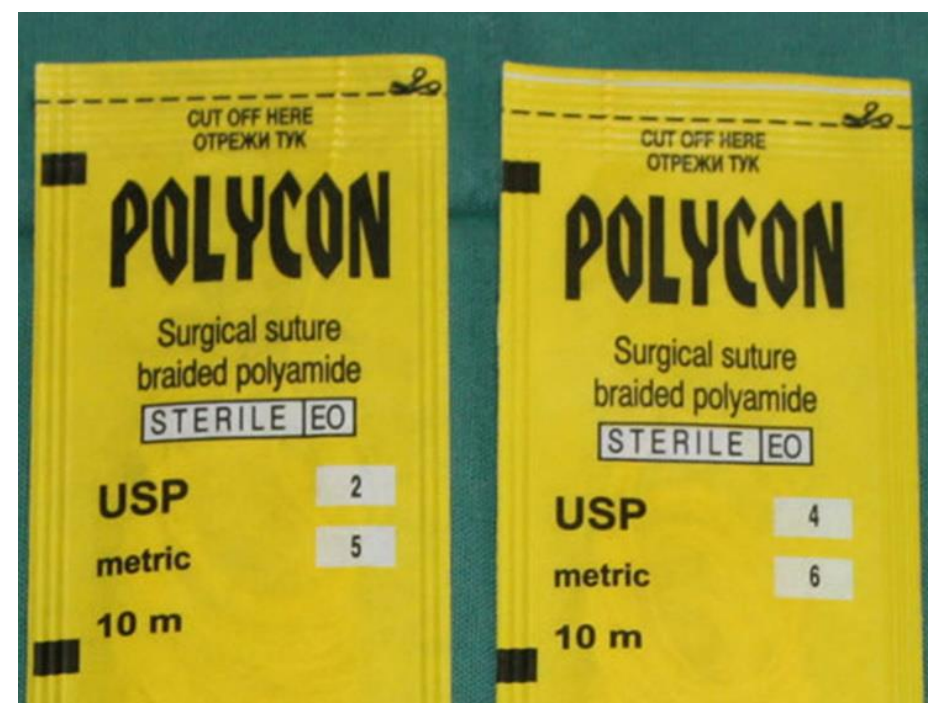

Fig. 5 Bulgarian semi-elastic, braided, antimicrobial polycaproamide (Polycon) sutures USP 2 or 4 are best used in the author's scarless closed approach temporal face lift.

\section{Indications}

The author's concept to lift the entire SMAS in a temporal direction using the scarless closed approach technique changes the "mask of tragedy" into a "mask of comedy" in cases of soft tissue laxity, early facial ptosis, for the purpose of beautification, rejuvenation, in cases of facelift revisions and blepharoplasties, lateral canthus ptosis, facial paralysis etc.

Contraindications could be uncontrolled acute, chronic and systemic diseases.

\section{Surgical method}

\section{Using needle perforation only - without skin incisions}

\section{1.a. First Higher Temporal SMAS Suture Lift. Direction to eyebrow and cheekbone}

Two lines A-B and A1-B1 are marked as parts of a rhombus inside the temporal area (Fig. 2.1.6). The line A-B represents the immobile subperiosteal (upper temporal line) and subtemporal (temporal fascia) stable fixation of the suture. Point A is located at the intersection point of the upper temporal line and the coronal line and point $\mathrm{B}$ is marked about 3-4 $\mathrm{cm}$ below at the coronal line. Line A1-B1 is the line of supragaleal attachment of the mobile SMAS (galea aponeurotica). Starting from A, a line A-A1 is marked at a 45 degree angle to line A-B in a direction pointing to the tail of the eyebrow. Point A1 is located at the end of that line in a distance from $\mathrm{A}$, depending on the laxity, usually at 3-5 cm away from $\mathrm{A}$.

Lines A-A1 and B-B1 represent the subgaleal/supratemporal passes of the suture, connecting the two attachment lines: immobile A-B and mobile A1-B1. They represent the direction of movement of the galea aponeurotica towards the temporalis fascia (Fig. 2.1.6). After injecting 
a local anesthetic, we use a No 11 scalpel blade to create skin perforations at entry points A, $\mathrm{B}, \mathrm{A} 1$ and B1. We use the tip of a fine mosquito clamp to widen the perforations and to ease the passing of the needle through the skin perforations without unnecessarily perforating the dermis. NB! Skin should not be captured. Capturing the dermis in the suture results in dimple formation, which is hard to remove.

The sequence of the needle entries should be convenient for both right or left handed surgeons and could be as follows: introducing the $\operatorname{Serdev}{ }^{\circledR}$ needle in the supragaleal pass along line A1-B1 directly under the skin (between the skin and galea where a thin layer of subdermal fat allows the needle to pass without any resistance). Starting at insertion point A1, the needle is introduced subdermally/supragaleally until it exits through point B1. Once its tip exits at B1, the surgical suture is loaded and introduced in the A1-B1 supragaleal plane.

The following subgaleal/supratemporal passes of the needle are directed from A to A1 and from B to B1. The final A-B passage of the needle and suture is inserted through the bone of the upper temporal line (subperiosteal) and is subtemporal (under temporalis fascia). The position of the suture in each plane has its own characteristics. In the subdermal/supragaleal A1-B1 plane the needle is movable laterally and is covered only by a thin layer of skin. In the subgaleal plane A-A1 and B-B1 the needle is introduced slightly deeper, and is again movable laterally (galea and skin are mobile tissues), and is covered by a thicker layer that includes skin, a thin layer of subdermal fat and galea.

As galea is attached to the skin in that region, pulling of skin in the form of a tunnel in lines A-A1 and B-B1 pulls galea as well and subgaleal needle entry in that tunnel is easy (no resistance). In this plane one has to avoid taking the temporalis fascia that is located below the needle. If immobile temporalis fascia is captured by the needle, the lateral movement of the latter is impossible without movement of the entire head of the patient. Such fixation is incorrect and the needle must be repositioned.

The subperiosteal and subtemporal A-B plane is a deep one and the needle is blocked (it cannot move in a lateral direction without moving the entire head).

Important: The needle should pass in and out through all 4 skin perforations in and out or out and in, without capturing any dermal tissue in order to prevent dimpling. While passing the suture in and out, make sure that the suture loop does not catch any hair in order to avoid introducing hair into the subdermal plane, which might cause a foreign body reaction and infection.

Once the suture loop is accomplished, the suture is tied and the surgical knot is made under medium elastic tension to prevent trauma to the tissue. 
After the knot is tied securely, one jaw of the mosquito hemostat clamp is used to free the skin perforations and reduce dimpling at these points. Some bulging effect (not visible, because it is covered by the hair) occurs due to suture and edema, and generally resolves in a week or two.

A.

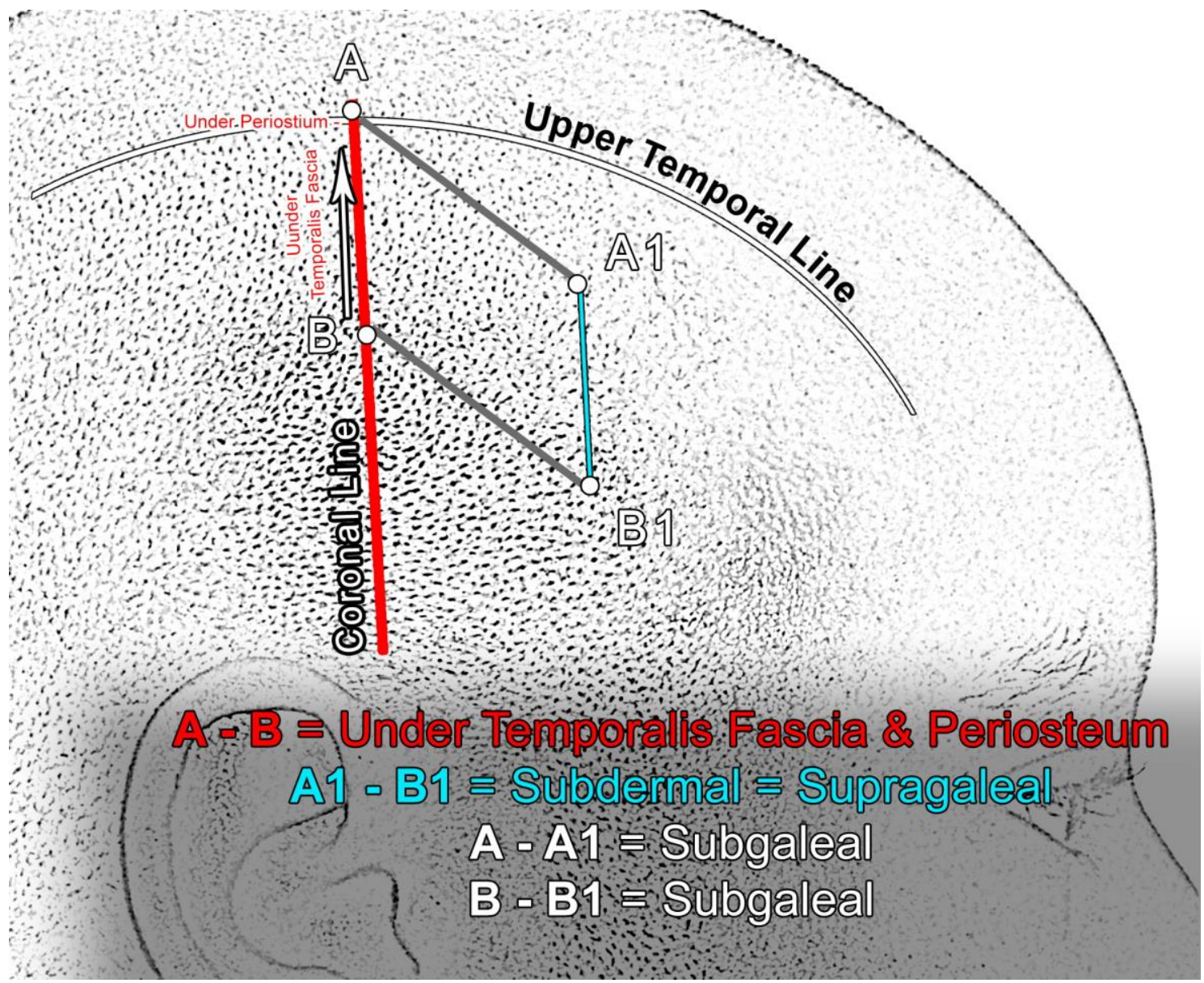

Fig. 6 A. First Suture: Upper temporal line and coronal line are marked. The immobile attachment is subperiosteal (upper temporal line) and subtemporal. The A-B line is $3-4 \mathrm{~cm}$ wide, in the coronal line (marked in red). Line A1-B1 is supragaleal mobile SMAS attachment (marked in blue) - it will be lifted to the A-B line of subperiosteal and subtemporal fixation. The connecting lines A-A1 (in the direction towards the eyebrow) and line B-B1 (in the direction towards the cheek-bone) are subgaleal passes only.

In cases of a very loose SMAS, found mostly in elderly patients, it is recommended to insert an additional suture below the first one to lift the medial and lower facial SMAS and soft tissue. 


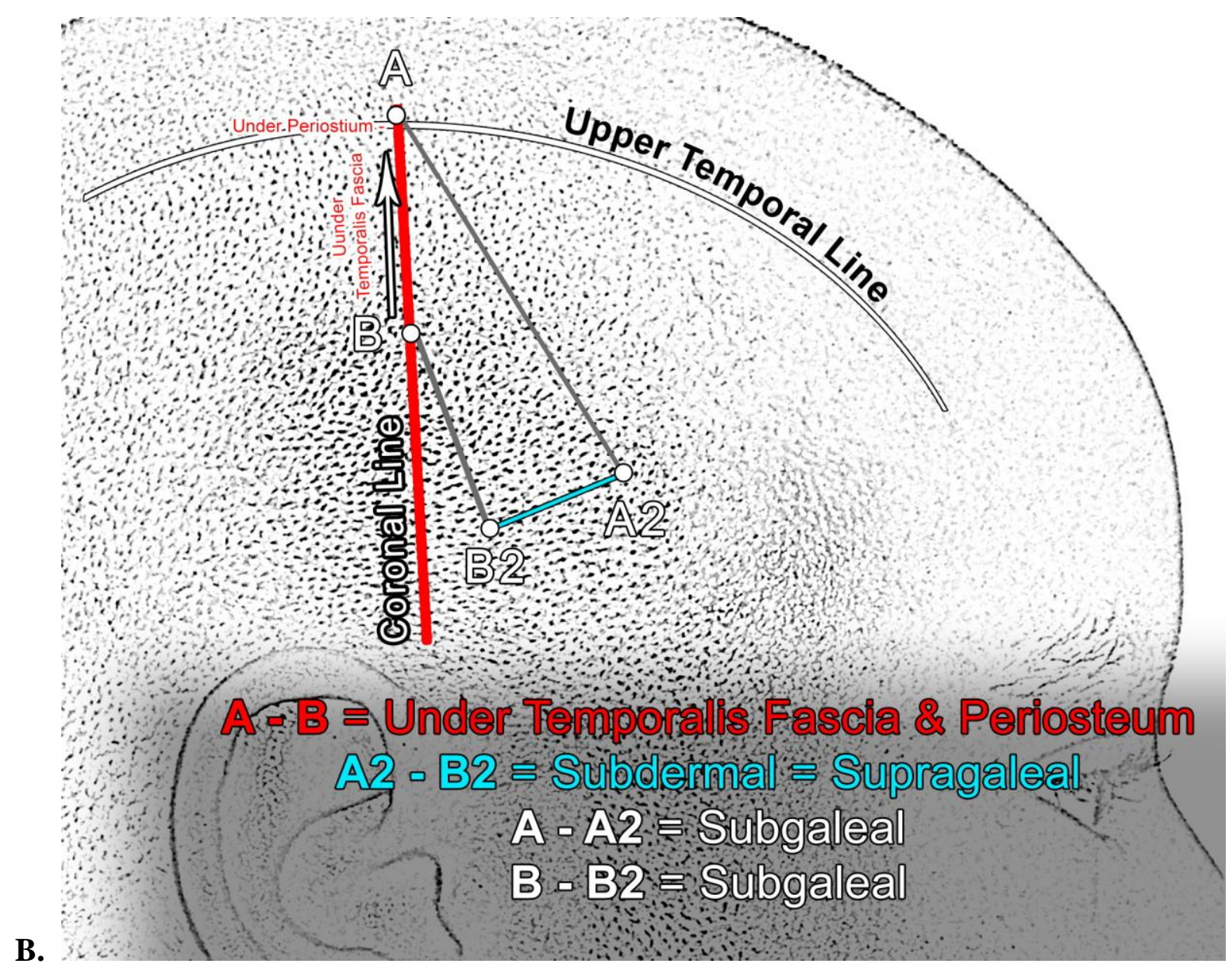

Fig. 6 B. Second (lower) suture: line A2-B2 of supragaleal fixation marked in blue will be lifted to the A-B line of subperiosteal and subtemporal fixation. Lines A-A2 and B-B2 in a direction towards the chin and lower face are subgaleal passes.

The popular temporal attachment (to temporal fascia) is not advisable, because temporalis fascia fibers are perpendicular and cannot hold a suture attachment with tension in a distal direction. The suture will slide down and the lift will not last as long (Fig. 2.1.7). 


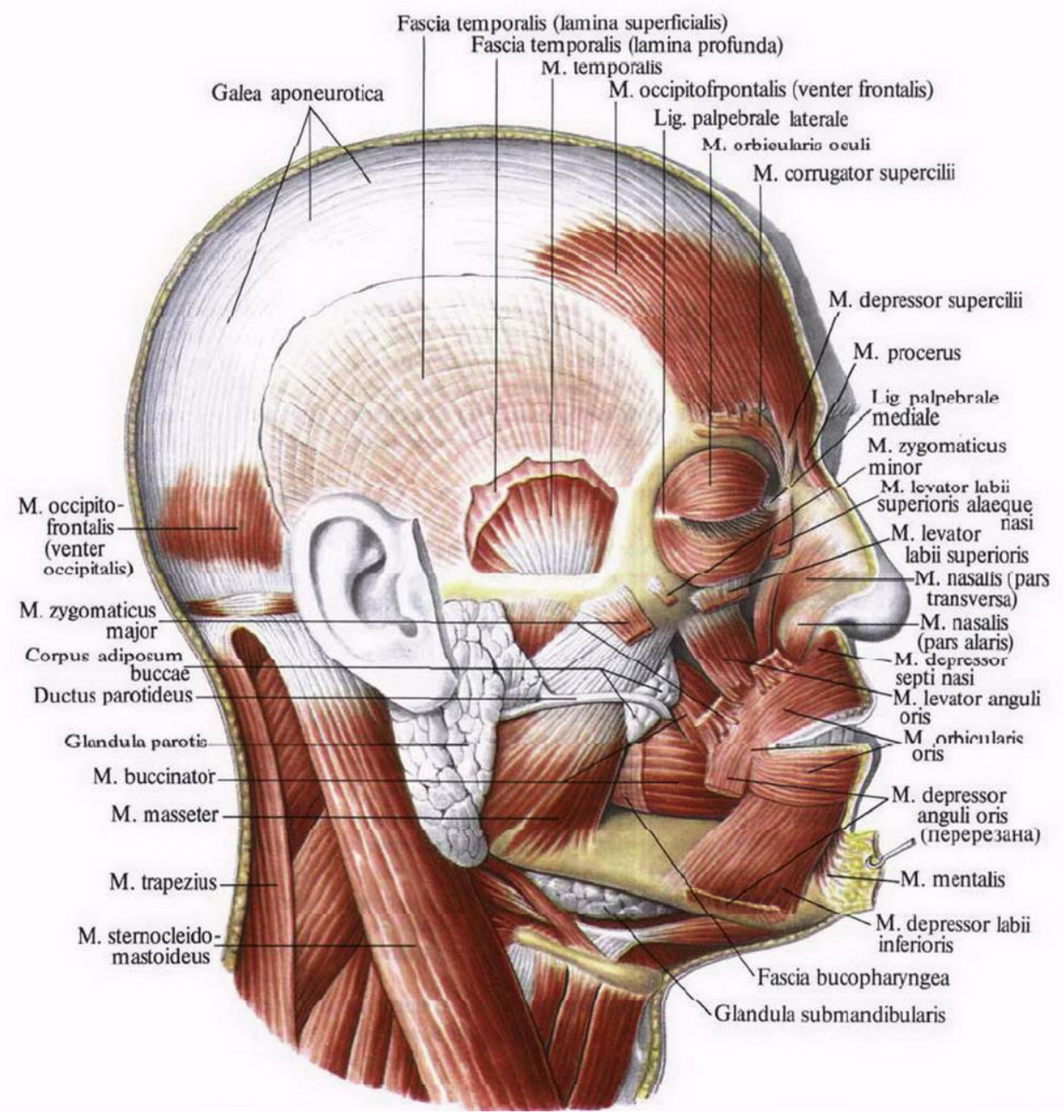

Fig. 7. Temporal fascia fibers* are in a distal direction and cannot hold the suture if the fixation is not attached to the upper temporal line bone and periosteum. *Anatomy figures from Sinelnikov - Atlas Of Human Anatomy, GIML, Moscow, 1963

\section{1.b. Second Lower Temporal SMAS Lift Suture}

A second (lower) line A2-B2 of galea fixation (below A1-B1) is marked (Fig. 2.1.6 B) and a second suture is added, mostly in elderly patients, when laxity in the lower face is still present after the first suture. This can be added simultaneously or at a later date, even years after the first upper temporal suture lift.

The needle and suture are introduced as described above (Fig. 2.1.6 B.). To summarize - in order to place the suture, the needle passes through 3 planes: supragaleal/subdermal (A2-B2), subgaleal (A-A2 and B-B2), and subperiosteal/subtemporal (A-B). 
Fig. 8 A-K. Stages of Second Lower Temporal SMAS lift suture without incisions.

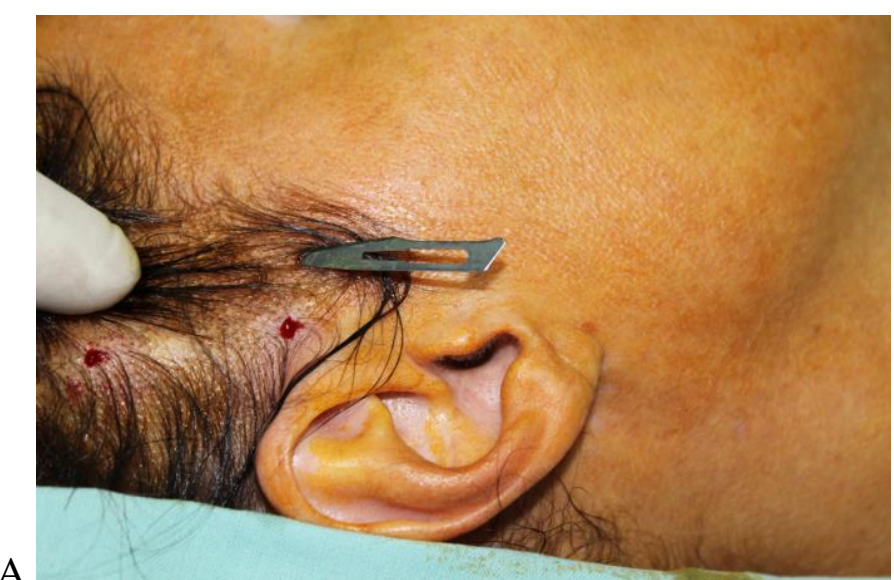

A.

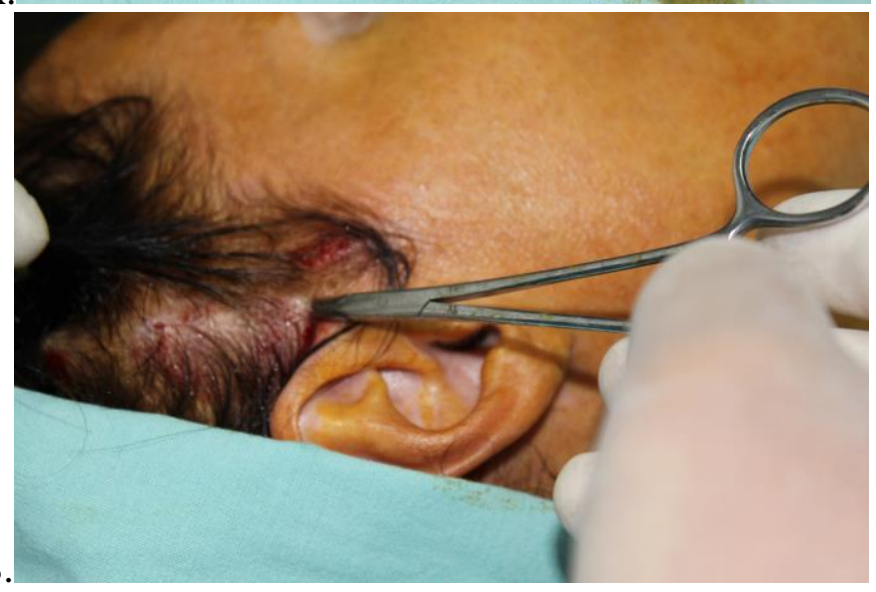

A. After infiltration of a local anesthetic, the skin is perforated in the selected points A, B, A2, and B2 using a number 11 scalpel blade.

B. Skin perforation points are widened with the tip of a fine mosquito clamp to facilitate the passing of the needle pass without capturing any dermis. 


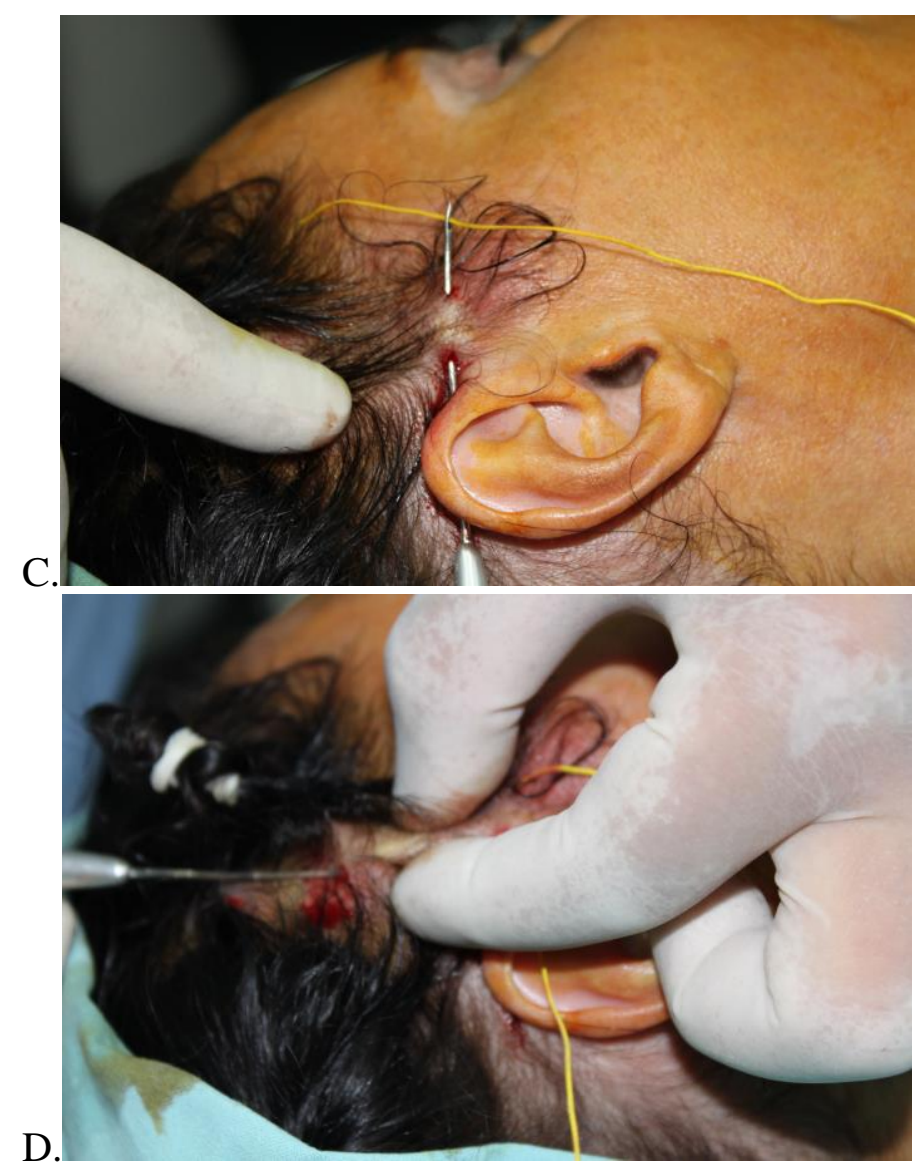

C. First needle pass (using Mini 60 Serdev $^{\circledR}$ needle) is made directly below the skin supragaleally in the thin fat layer between the skin and galea aponeurotica. The needle is loaded and the suture is placed into the supragaleal plane.

D. The connecting pass B-B1 is located subgaleally/supratemporally in the tunnel (free space) formed by lifting the skin and galea. As skin and attached galea are lifted, the needle is introduced in the free space between galea and temporalis fascia through the tunnel that is created with two fingers. 


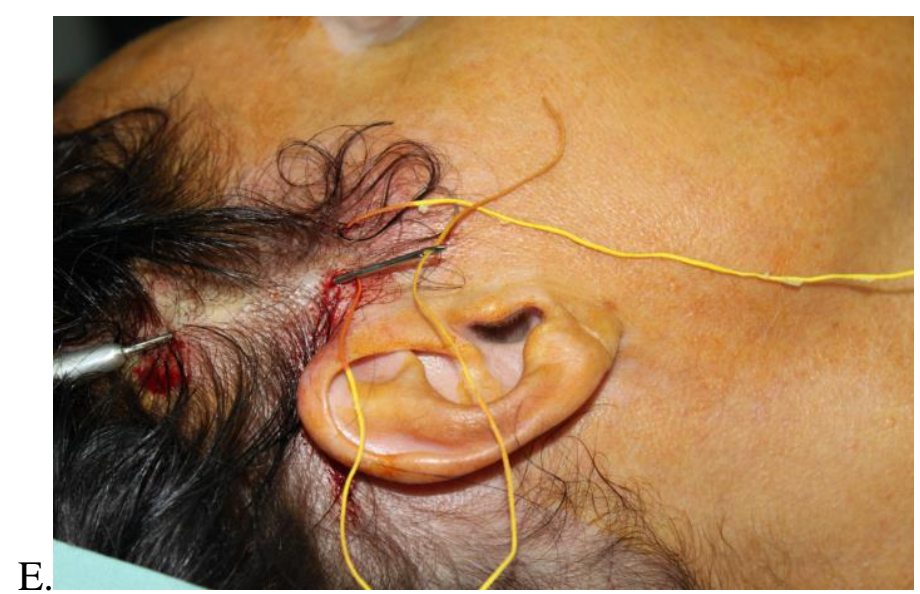

E.

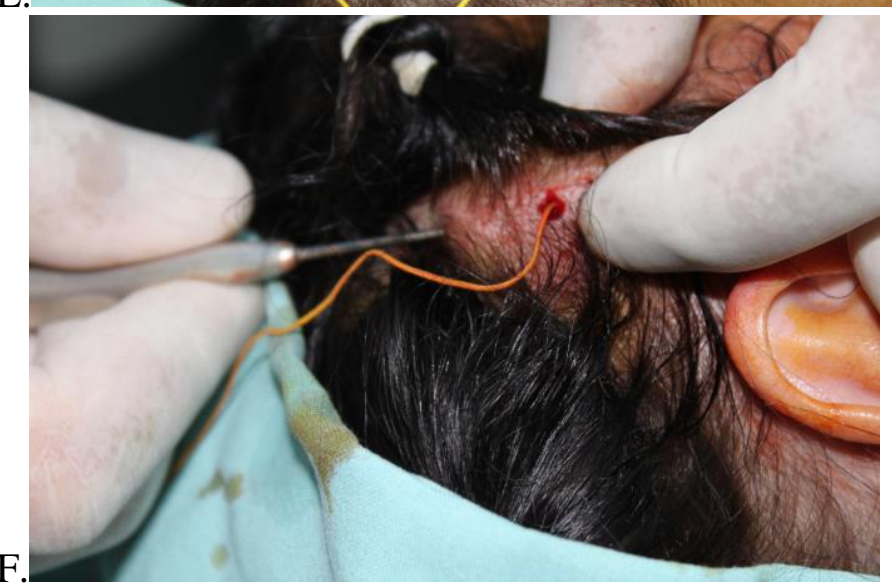

E. The suture is loaded on to the needle and will be introduced subgaleally in line B-B1. NB1 Take care not to insert hair subdermally with the suture loop.

F. The connecting pass A-A1 is located in the subgaleal/supratemporal level. The skin and attached galea are lifted and the needle is introduced in the free space between the galea and temporalis fascia through the tunnel. The needle will be loaded and the suture introduced subgaleally in A-A1. 


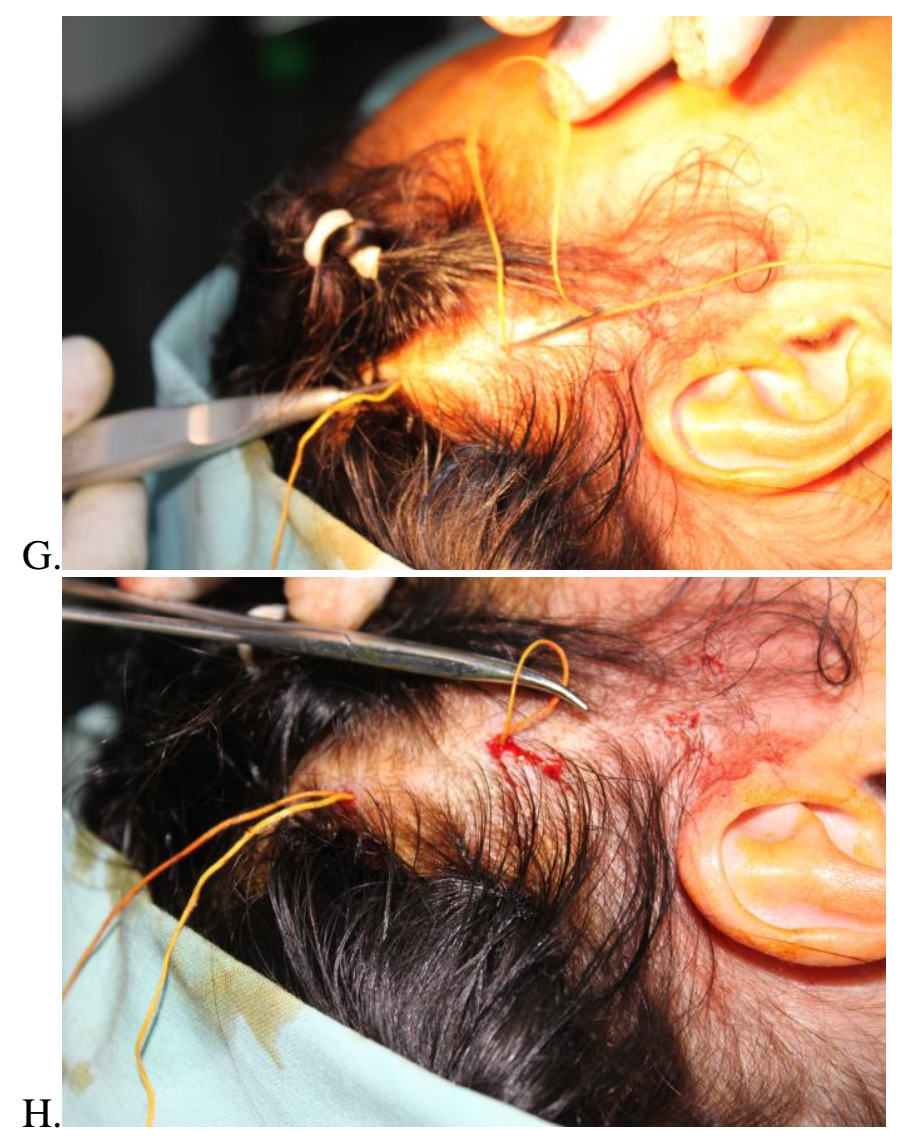

G. The needle is introduced through the bone and periosteum of the upper temporal line and subgaleally in line A-B. Then the needle is loaded.

$\mathrm{H}$. The suture is introduced in the subperiosteal and subtemporal line A-B. With the tip of a mosquito instrument, the assistant prevents hair from being inserted with the suture loop. Having successfully removed any interposed hair, the suture is carefully submerged. NB! Use this maneuver every time to prevent introducing hair/foreign body in the soft tissue. 


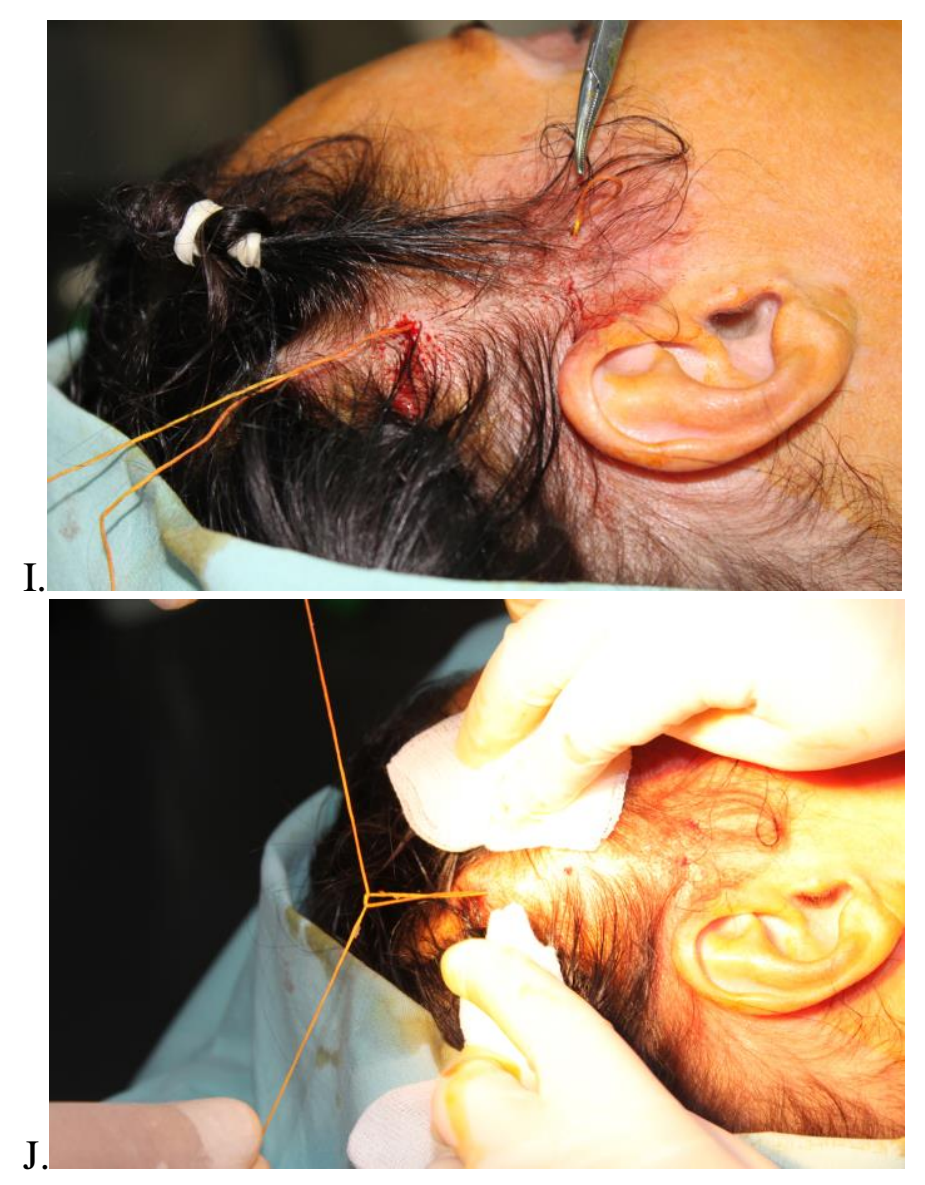

I. The suture circle is finalized. Both suture ends are at point A.

J. Again, take care to prevent the insertion of hair during tightening of the suture. 


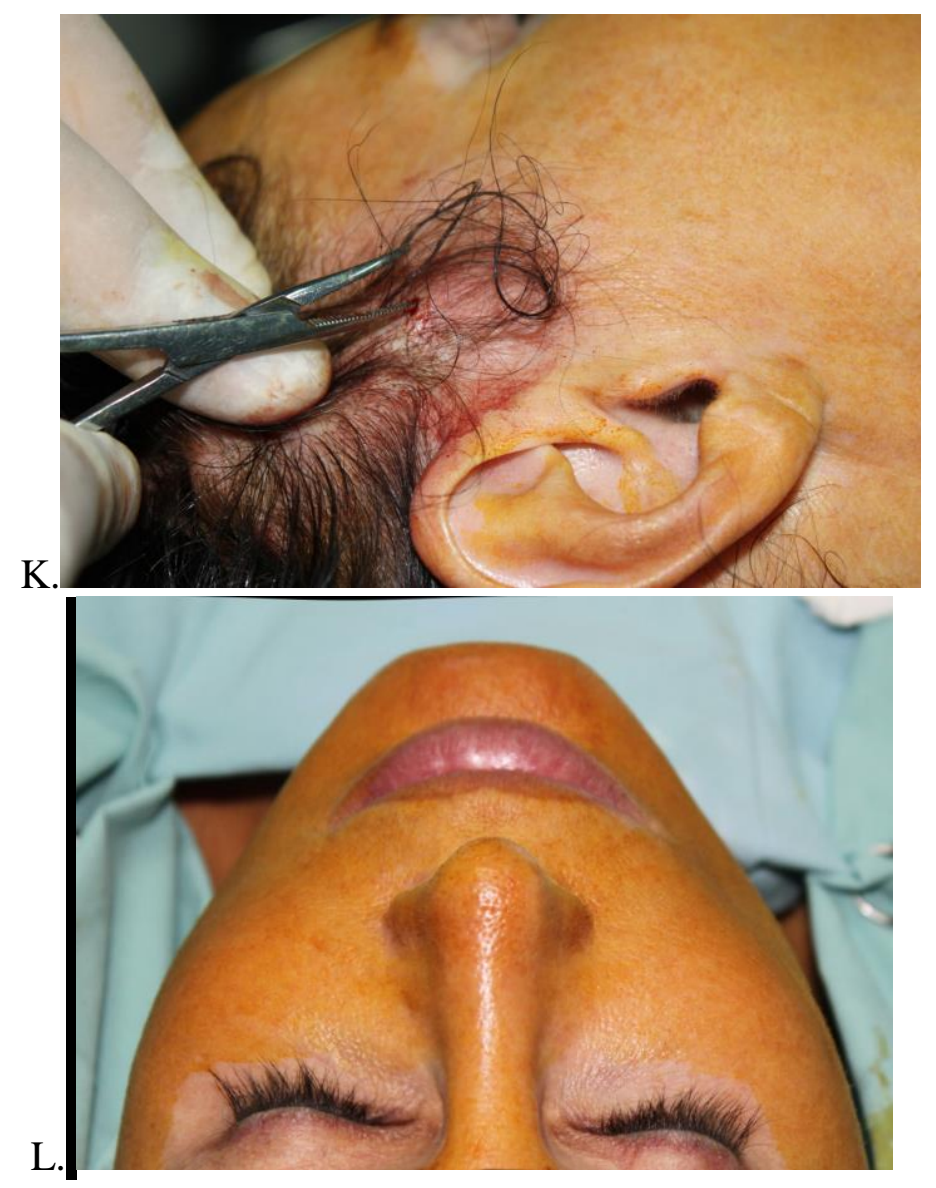

K. Use a mosquito clamp to free any attachments of skin to the suture.

L. Result after unilateral right-side temporal lift: the right side of the face is elongated; the eyebrow and lateral canthus of the eye are lifted; the cheekbone is positioned higher; SMAS and skin are tighter.

\section{Temporal Lift using a minimal hidden skin incision:}

At the beginning of the testing period, the author was using a $3 \mathrm{~cm}$ temporal incision at the coronal A-B line, which is more comfortable for beginners because they can see the subperiosteal and subtemporal, subgaleal and supragaleal attachment. This technique is started with local anesthesia and a $3 \mathrm{~cm}$ A-B incision is made along the coronal line. The incision of the skin and subdermal fat makes the red vascularised galea visible. After the galea is opened with a mosquito clamp, the white shiny temporal fascia can be seen (Fig. 2.1.9). A blunt subgaleal dissection follows. It should be very easy because there are no stable attachments between these two fascias - galea and temporal fascia. From this moment on, the technique is performed as described in 2.1.1. Line A1-B1 is a supragaleal/subdermal pass, A- 
A1 and B-B1 are subgaleal passes, performed under visual control, and A-B is a subperiosteal and subtemporal pass under visual control as well. A very important part of the technique is to prevent insertion of hair with the suture loop into the subdermal plan. This will lead to granuloma formation and local infection. Deep engagement of the temporal muscle should be avoided to prevent pain, which is described by patients as a headache. Furthermore, the temporal muscle will be cut by the suture, which will become loose and the lifting effect will be lost. The galea, presenting the upper SMAS is pulled up and fixed to the upper temporal line and temporal fascia with one or two sutures on each side, under elastic tension. Thus, the whole SMAS is pulled up in a temporaldirection. Next, the skin is closed with single interrupted stitches and no bandage is necessary. A hair wash is recommended on the following day, in order to remove any residual blood. Wound stitches are removed 7 days later.

A)

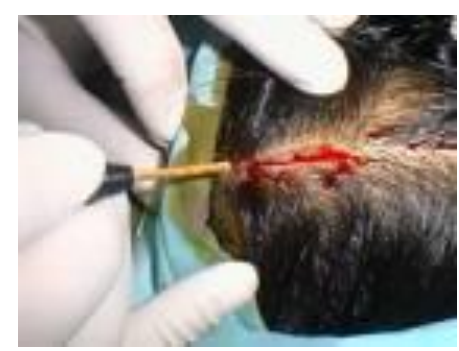

A)

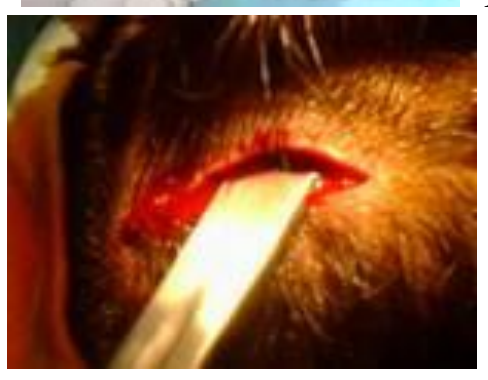

\section{D)}

B)

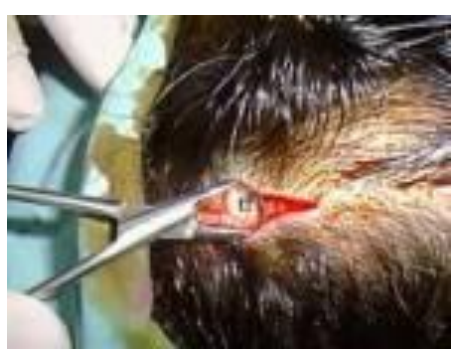

C)

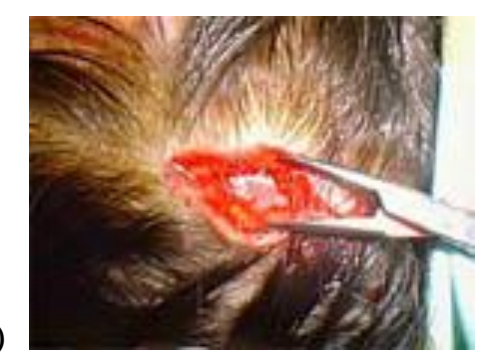

Fig. 9 A. Skin incision; B., C. blunt opening of skin and the red galea. The white, shiny temporal fascia is visible underneath; D. Blunt dissection between galea and temporal fascia.

\section{RESULTS}

Between 1993 and 2001, this Temporal lift suture technique was performed on 1427 patients, ranging in age from 19 to 68 years. These patients were followed up for 3 or more years. In the first 20 cases, the open technique by a small incision in the coronal line was used. Later on, with the introduction of Serdev ${ }^{\circledR}$ needles, the Temporal Suture technique through small skin perforation points (closed approach technique) became the preferred method. These operations are ambulatory. After washing their hair, most patients resumed their normal social activities on the same or on the next day. 
The temporal SMAS lift has stable effects on the supra-zygomatic area: it reduces the crows feet wrinkles, lifts the eyebrow tails and the lateral cantus of the eyes, lifts the cheekbones and tightens the skin. The effects on the lower face are less expressed. The SMAS elevates the oral commissure as well; it improves the skin texture; reduces cheek flaccidity; gives a clearer outline of the jaw. Generally, the method gives excellent results in younger and middle aged patients whose lower face flaccidity is minimal to medium. The facial tissues are repositioned to the desired higher youthful position. The temporal hair is preserved. There are no visible scars, no signs of operative intervention, and no "operated-on" appearance. A moderate feeling of tension could be present for a few hours to a couple of days.

The most important factor in face lifting is its longevity. Numerous factors act against face stability, such as gravity and facial movements. The longevity of the result in the closed approach suture method is guaranteed due to the stable SMAS fixation to the periosteum. This is best seen years after the surgery in cases of a unilateral temporal SMAS lift in facial paralysis, posttraumatic and postoperative canthal abnormalities etc. (Fig. 2.1.14).

\section{CLINICAL CASES}

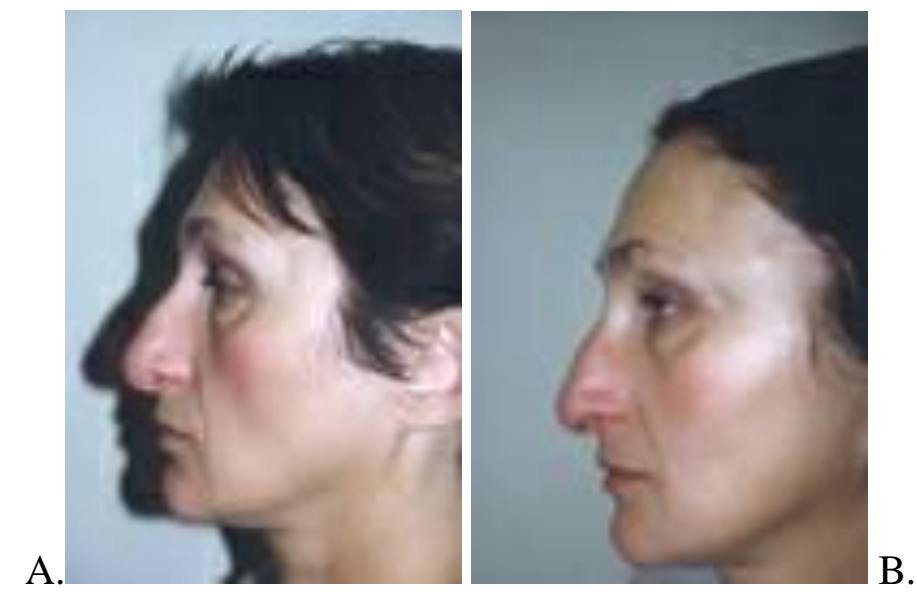

Fig. 10 A. before, B. after a temporal SMAS lift. Visible elevation of the eyebrow tail and the lateral cantus of the eye, reduction of the crows-feet wrinkles, elevation of the cheekbone tissue; tightening, better texture and beautification of the skin.
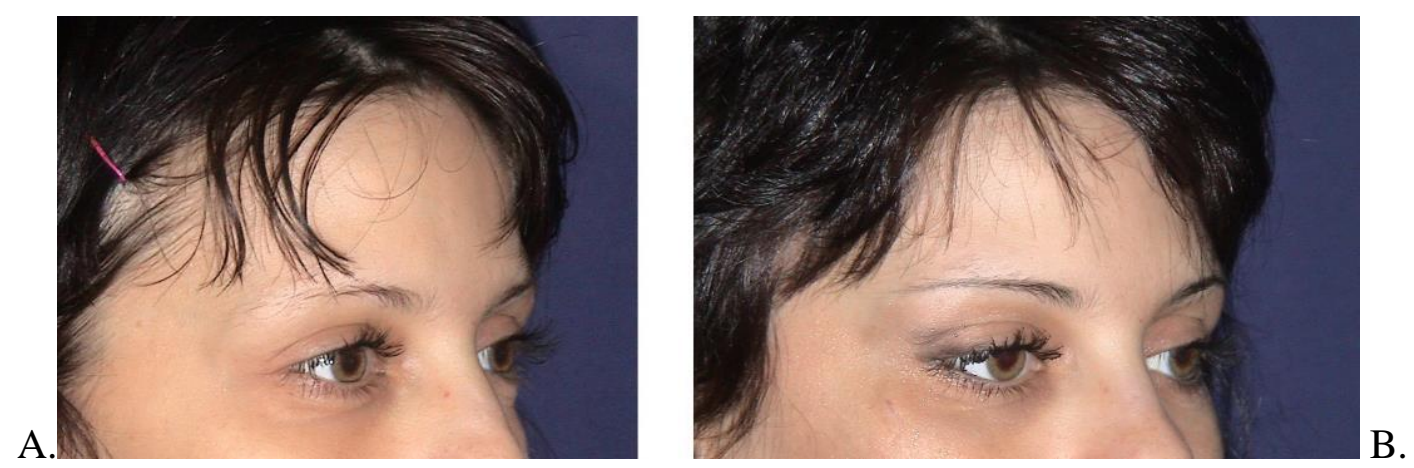

Fig. 11 A. before, B. after a temporal face lift using Serdev Suture ${ }^{\circledR}$ in a young patient. Angles of the eyes and eyebrows are changed resulting in beautification. 


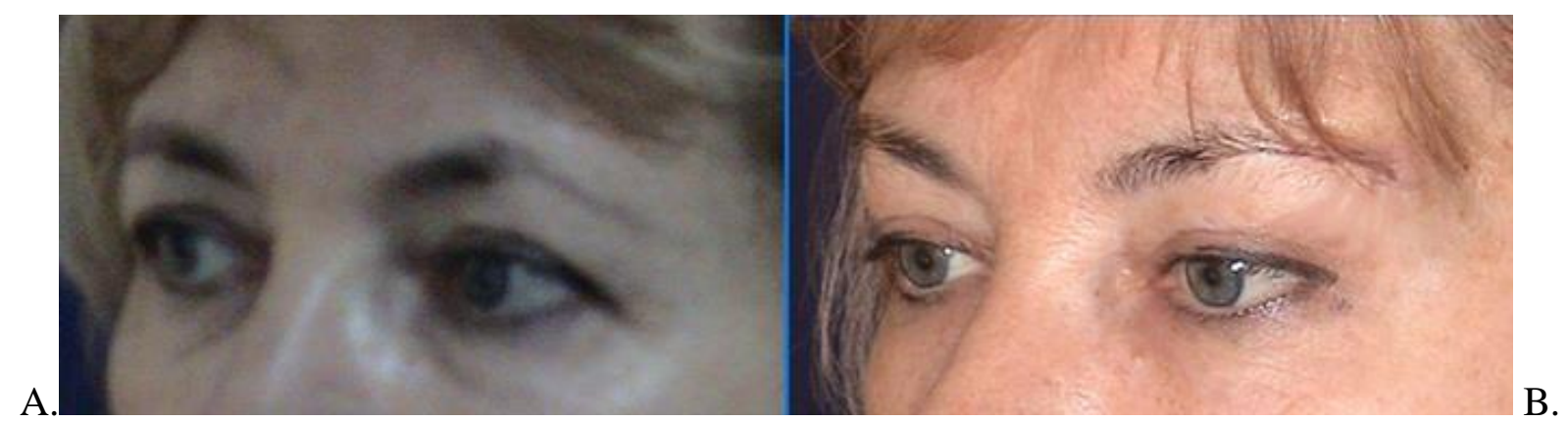

Fig. 12 A. before, B. after a temporal face lift using Serdev Suture ${ }^{\circledR}$ in a 58 y.o. patient. Angles of the eyes and eyebrows are changed resulting in rejuvenation and beautification.

A.

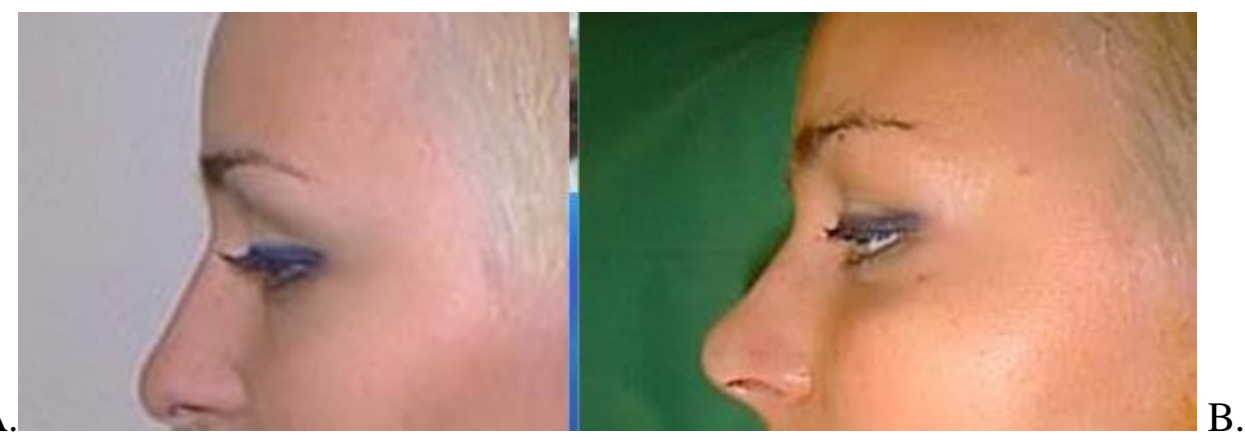

Fig. 13 A. Before and B. immediately after a temporal SMAS lift and author's tip rotation and columella sliding rhinoplasty. The absence of visible signs of the operation permits an immediate return to social life. Author's techniques in rhinoplasty do not require tampons and plaster fixation.
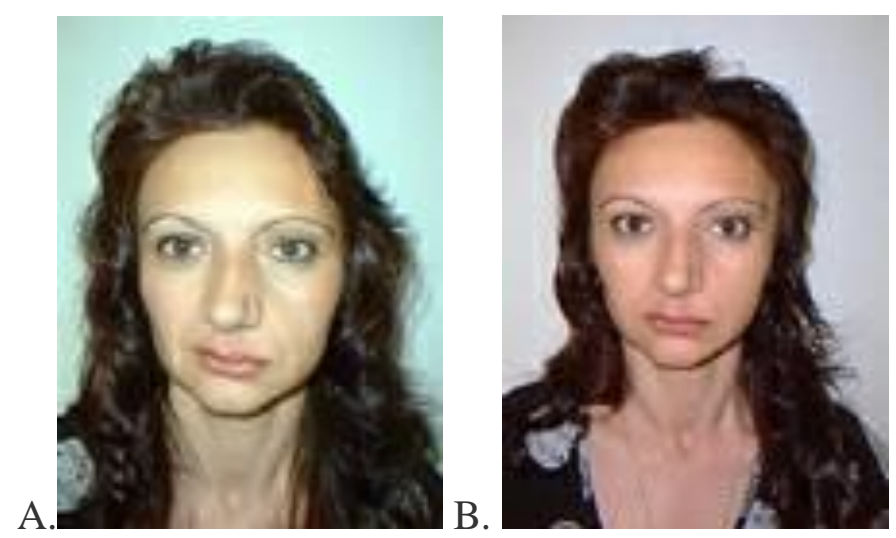

Fig. 14 A. Before and B after unilateral temporal SMAS lift in facial paralysis. The whole left side is elevated and the nose is repositioned in the middle. 


\section{Risks and complications}

Only 7 patients described the tension as uncomfortable for one or two days. During the first week 12 patients reported headache. Lower eyelid swelling may appear on the third day after surgery due to gravity and can be prevented by resting in a supine position during the first two days. Five patients had unilateral lower lid bruising and four other patients - bilateral. Some invisible bulging in the temporal area could be palpated for few weeks.

Seven patients reported unilateral liquid and crust formation at the perforation points. The reason was subdermal insertion of hair by the suture loop. After the hair was removed, the wounds healed in approximately two to four days. One foreign patient had the same problem in her country and the surgeon removed the suture 5 weeks after surgery but even then no ptosis appeared due to the progressive fibrosis formation. No other infections, hematomas or damage on the facial nerve were observed. After some months two patients could not see the difference in their appearance despite the photograph demonstrations, contesting the aesthetic result. The effect of lifting angles was not satisfactory for 5 patients, 2 years after the procedure. With 3 of them, additional SMAS lifting was possible after 3 to 5 years, and the lower suture for temporal SMAS lift was added.

\section{DISCUSSION}

Currently, there are plenty of techniques used for face-lifts, but none of them can respond to the need for beautification in young people. Such techniques are: conventional rhytidectomy, composite face-lifting, deep layer rhytidectomy, sub-SMAS, extended face-lifting, subcutaneous temporofacial lift combined with SMAS suspension, medial SMAS lift with aggressive temporal skin removal, temporal lift via blepharoplasty approach. Stretching the skin solely is obsolete. New techniques were proposed, such as endoscopic, subperiosteal, extended face-lifts etc. There is no general agreement and no definitive answer as to which operative technique is most effective or preferable for each specific case. This is due to the subjective nature of aesthetics, aspirations and to the variability of skills and anatomy.

In the past few years, the demand for non-invasive or minimally invasive surgery for beautification or rejuvenation, minimal trauma, and short recovery and downtime, corresponding to the modern lifestyle, have been on the rise. The suture method for temporal SMAS lift described in this chapter is the most preferred option by our patients as an optimal solution for upper (and total) face beautification and rejuvenation that preserves the natural look. It is suitable for beautification of young people as well, and is very much preferred in Asians and Afro-Americans, known for forming scars and keloids.

\section{Conclusions}

The temporal SMAS lift is a nice "coffee-time" and "weekend" ambulatory procedure that gives a pleasing rejuvenation and beautification of the skin, eyes, brows, and cheekbones. Most importantly, it changes the expression into fresh, younger and more shiny one. 
Complication rate is very low and the methods to prevent and solve those complications are easily handled. In young women, only one suture per side is usually enough to lift the lateral canthus of the eye, the eyebrow and to pull the ptotic malar fat into place, which forms a nice malar eminence. It is also possible to combine the temporal lift by suture with other procedures: the author uses additional suture methods for brow, mid face, cheekbone, and lower SMAS lift, simultaneous rhinoplasty, chin and lip augmentation, fat reduction and/or augmentation, skin resurfacing, blepharoplasty to obtain facial beautification. The closed approach Serdev Suture ${ }^{\circledR}$ method for temporal SMAS lift provides a safe and effective beautification and rejuvenation technique with a very short downtime, and immediate return to social life.

\section{REFERENCES}

[1] Serdev, N.P. Suture Suspensions for Lifting or Volume Augmentation in Face and Body (English version), presented at the 2nd Annual Meeing of the National Bulgarian Society for Aesthetic Surgery and Aesthetic Medicine, Sofia, 18 March 1994, Int J Aesth Cosm, 2001,1:1, 2561-2568

[2] Serdev, N. P. Forehead Subperiosteal Masklift in Combination with McIndoe Facelift Technique and Profile Correction. The 7th IPRAS Congress European Section, Berlin, Germany, June 2-5, 1993.

[3] Serdev N. P. Temporal SMAS lift without skin excision In: Lip Augmentation During Mask and SMAS Lift Procedure, AAARS Annual Meeting, New Orleans, USA, October 5-9, 1994.

[4] Serdev, N.P. Temporal SMAS Lifting of the Face. Life Surgery Workshop. Unidad Medica Clinica Del Country, Bogota D.C., Colombia, November 8-10, 1999.

[5] Serdev, N. P. SMAS Lifting of the Face by Minimal Incisions - the Serdev Technique. Life Surgery Workshop sponsored by International Academy of Cosmetic surgery and the Balkan Academy of Cosmetic Surgery, held at the Krilig Clinic in Caracas, Venezuela, November 12-18, 1999.

[6] Serdev, N. P. Principles of Face Beautification, Ier Congresso Internacional de Cirurgia Cosmetica, Buenos Ares Argentina, 31 Octubre - 1 de Noviembre 1999.

[7] Serdev, N.P. Temporal SMAS lift, Lecture and Life Demonstration, 1st World Congress of Cosmetic Surgery with Life Demonstrations, Edsa Shangri-La Manila and Quezon City Medical Center, February 25-27, 2000.

( http://www.mpint.co.jp/apacs/Congress2000/con007.htm ) 
[8] Serdev, N.P. Temporal SMAS Lifting of the Face, Combined with Liposuction and Chin Augmentation Using Suture. Life Surgery Workshop, Tel Aviv, Israel, April 20-24, 2000.

[9] Serdev, N. P. Principles of face beautification, The 3-rd World Congress of ISAS, Tokyo, April 8-10, $2000,9 \mathrm{~W} 58$.

[10] Serdev, N.P. Lifting del SMAS con Una Pequenna Incision Temporal, VIIIas Journadas Mediterraneas de Confrontaciones Terapeuticasen Medicina y Cirurgia Cosmetica, Sitges, Barcelona, March 16-19, 2000.

[11] Serdev, N.P. Facial Rejuvenation by Minimal Skin Incisions, International Congress "Refinements in Aesthetic Surgery" Oradea, Romania, June 22-24.

[12] Mitz, V, Peyronie M. The superficial musculoaponeurotic system (SMAS) in the parotid and cheek area. Plast. Reconstr. Surg. 1976; 58: 80.

[13] Miura Y, Moura PD, Ramasastry S, Hochberg J. Can we simplify the nomenclature of the fascial lyers of the temporo parietal region? OnLine J Plast Reconstr Surg, Nov 1997;1: 1.

[14] Stuzin, J. M., Baker, T. J., Gordon, H. L., and Baker, T. M. Extended SMAS dissection as an approach to midface rejuvenation. Clin. Plast. Surg. 1995; 22: 295.

[15] Connell, B. F., and Marten, T. J. The male foreheadplasty: Recognizing and treating aging in the upper face. Clin. Plast. Surg. 1991; 18: 653.

[16] Aston, S. J. Platysma-SMAS cervicofacial rhytidoplasty. Clin. Plast. Surg. 1983;10: 507. Barton, F. E., Jr. The SMAS and the nasolabial fold. Plast. Reconstr. Surg. 1992; 89: 1054.

[17] Bosse, J. P., and Papillon, J. Surgical Anatomy of the SMAS at the Malar Region. In Transactions of the 9th International Congress of Plastic and Reconstructive Surgery. New York: McGraw-Hill, 1987: 348.

[18] Cardoso de Castro, C. The role of the superficial musculoaponeurotic system in face lift. Ann. Plast. Surg. 1986; 16: 276.

[19] Stuzin JM, Wagstrom L, Kawamoto HK, Wolfe SA. Anatomy of the frontal branch of the facial nerve: The Significance of the Temporal Fat Pad. Plast Reconstr Surg 1989; 83: 265-71.

[20] Ramirez OM, Maillard GF, Musolas A. The extended Subperiosteal Face lift: A definitive Soft-tissue Remodeling for Facial Rejuvenation. Plast Reconstr Surg 1991; 88:22736 .

[21] Tolhurst DE, Carstens MH, Greco RJ, Hurwitz DJ. The Surgical Anatomy of The Scalp. Plast Reconstr Surg 1991; 87: 603-12. 
[22] Larrabee Jr., W.F., Makielski, K.H. Surgical Anatomy of the face. New York: Raven Press, 1993: 41-48.

[23] Hochberg J, Kaufman H, Ardenghy M. Saving The Frontal Branch during a Low Frontoorbital Approach. Aesth Plast Surg 1995; 19: 161-163.

[24] Core GB, Vasconez LO, Graham III, HD Endoscopic Browlift. Clin. Plast. Surg.1995; 22: 619-31.

[25] Bostwick III, J., Eaves, F.F., Nahai, F. Endoscopic Plastic Surgery. Quality Medical Publishing, Inc. St. Louis, MO, 1995: 86-129. S.E. The Deep Temporal Lift: A multiplanar, lateral Brow, Temporal, and Upper face Lift. Plast. Reconstr Surg 1996; 5: 928-37.

[26] Bostwick III, J., Eaves, F.F., Nahai, F. Endoscopic Plastic Surgery. Quality Medical Publishing, Inc. St. Louis, MO, 1995: 86-129.

[27] De la Fuente A, Santamaria AB Endoscopic subcutaneous and SMAS facelift without preauricular scars.Aesthetic Plast Surg1999 Mar-Apr; 23: 119-24.

[28] Kamer FM, Frankel SMAS rhytidectomy versus deep plane rhytidectomy: an objective comparison.ASPlast Reconstr Surg 1998 Sep; 102 (3): 878-81.

[29] Hagerty RC, Scioscia PJThe medial SMAS lift with aggressive temporal skin takeout.Plast Reconstr Surg 1998 May; 101 (6):1650-6.

[30] Gray H, Goss CM. Anatomy of The Human Body. Philadelphia: Lea and Febiger, 1966: 375-99.

[31] Hamra ST. The tri-plane face lift dissection. Ann Plast Surg 1984 Mar; 12 (3): 268-74.

[32] Casanova R, Cavalcante D, Grotting JC, Vasconez LO, Psillakis JM. Anatomic basis for Vascularized Outer-Table Calvarial Bone flaps. Plast. Reconstr Surg 1986; 78: 300-8.

[33] Abul-Hassan, HS, Ascher, GD, Acland, RD. Surgical Anatomy and Blood Supply of the Fascial Layers of the Temporal Region. Plast Reconstr Surg 1986; 77: 17-24.

[34] Hamra ST. The deep-plane rhytidectomy. Plast Reconstr Surg 1990 Jul; 86 (1):53-61. Mitz V, Use of deep planes in surgery of rejuvenation of the face Chirurgie 1991; 117 (4): 278-86.

[35] De La Plaza R, Valiente E, Arroyo JM, Supraperiosteal lifting of the upper two-thirds of the face.Br J Plast Surg 1991 Jul; 325 :32- 44.

[35] Caix P, Goin JL, Modschiedler T. "Total SMAS lift" or deep facial lift by temporal approach. Initial eport. Ann Chir Plast Esthet 1992 Jan; 37 (1): 67-74. 
[35] Bonnefon ADeep "en bloc" facial lift" Ann Chir Plast Esthet 1992 Jan; 37 (1), 85-94 Hamra ST, Composite rhytidectomy.Plast Reconstr Surg, 1992 Jul; 90 (1): 1-13.

[35] Teimourian B, Delia S, Wahrman A, The multiplane face lift.Plast Reconstr Surg 1994 Jan 93; 1: 78-85.

[36] Campiglio GL, Candiani P. Anatomical study on the temporal fascial layers and their relationships with the facial nerve.Aesthetic Plast Surg 1997 Mar-Apr; 21 (2): 69-74.

[37] Byrd HS The extended browlift. Clin Plast Surg, 1997 Apr; 24 (2): 233-46.

[38] Honig JF Concepts in face lifts. State of the art Mund Kiefer Gesichtschir 1997 May; 1(Suppl): 1S21-6.

[39] Bonnefon A. Deep vertical lift and its development regarding the central facial area and lower two-thirds of the neck. Our technique, Ann Chir Plast Esthet, 1999 Dec: 609-16.

[40] Quatela VC, Sabini P. Techniques in deep plane face lifting. Facial Plast Surg 2000 May; 2: 193-209.

[41] Mittelman H, Newman J. Smasectomy and imbrication in face lift surgery.Facial Plast Surg 2000 May; 2: 173-82.

[42] Maloney BP, Schiebelhoffer J. Minimal-incision endoscopic face-lift. Arch Facial Plast Surg 2000 Oct-Dec; 4: 274-8.

[43] Achauer BM, Adair SR, VanderKam VM, Combined rhytidectomy and full-face laser resurfacing. Plast Reconstr Surg, Dec 2000; 106: 1608-11. 


\section{SUPPLEMENT}

\section{SUPRA-TEMPORAL LIFT}

The Supra-temporal lift presents A-B line fixation of the mobile galea aponeurotica at the hairline to the A1-B1 periosteum of the upper temporal line behind the hairline (Fig. 2.2.1.).

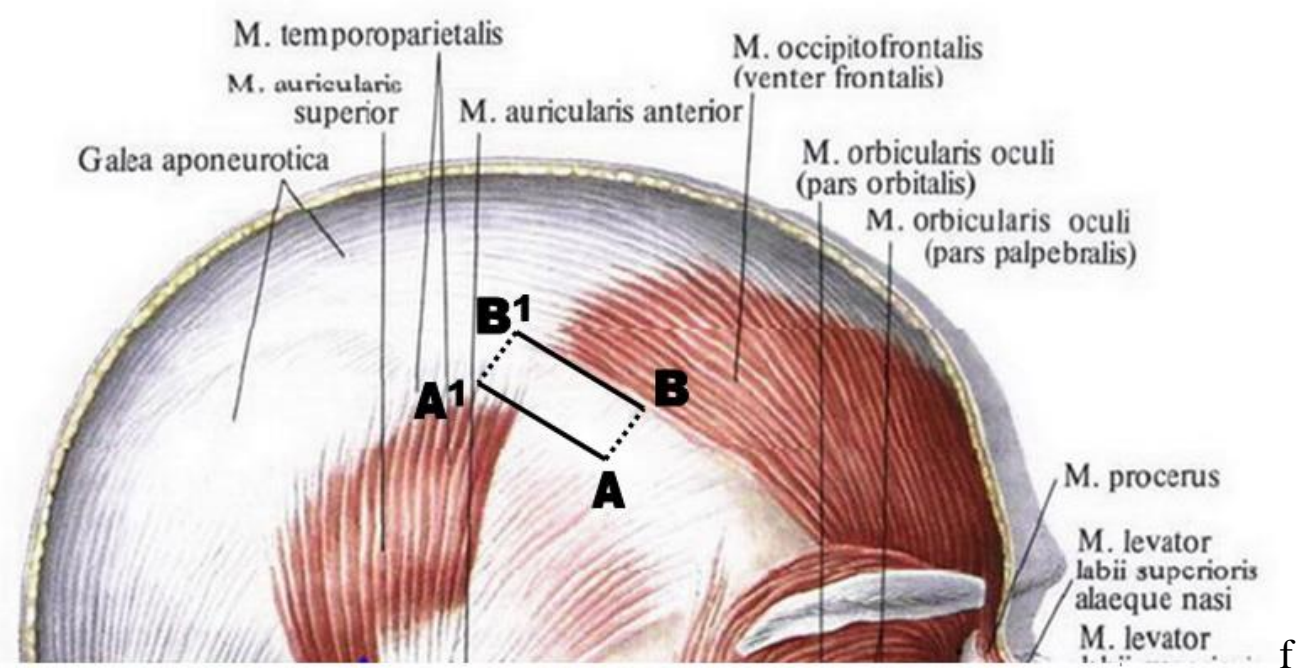

Fig. 15. Line A-B is supragaleal/subdermal (mobile fixation), line A1-B1 is subperiosteal (immobile fixation), and connecting lines $A-A 1$ and $B-B 1$ are subgaleal. *Anatomy figures from Sinelnikov - Atlas Of Human Anatomy, GIML, Moscow, 1963

Received: June 17, 2014 